\title{
GUERRA FISCAL: UMA AVALIAÇÃO COMPARATIVA ENTRE ALGUNS ESTADOS PARTICIPANTES*
}

\author{
Sidnei Pereira do Nascimento ${ }^{\S}$
}

\begin{abstract}
RESUMO
Na década de 1990 muitas unidades da Federação concederam isenções tributárias para atrair investimentos. No ambiente competitivo da economia brasileira após 1997, a pesquisa comparativa avalia o impacto da guerra fiscal nas receitas do ICMS, na geração de postos de trabalho na indústria e no PIB por setor, comparando-se o Estado de São Paulo com outros Estados da Federação. Foram utilizados dois modelos econométricos, um que compara alterações nas variáveis entre os Estados e entre os períodos, antes e após a guerra fiscal, e o outro, que capta mudanças na taxa de crescimento das variáveis entre os períodos. As estimativas mostram que os Estados avaliados, individualmente ou em conjunto, apresentam alterações significativas na taxa de crescimento do PIB industrial, em comparação ao Estado paulista, depois da intensificação da guerra fiscal. Os mesmos resultados parecem não valer para a geração de empregos na indústria e para as receitas do ICMS.
\end{abstract}

Palavras-chave: guerra fiscal, federalismo, desenvolvimento econômico, sistema tributário, concentração industrial.

\begin{abstract}
Many states of the federation have offered tax exemptions to enterprises, aiming to attract investments in the nineties. Considering this competitive environment, this study evaluates, comparatively, the impact of revenues from ICMS - Tax on Goods and Services - on employment generation in the industrial sector and on the sectional GDP, comparing the São Paulo state with the other states of the federation. Two econometric models were utilized, being one the "Differences in Differences", which compares changes in the variables among the states and between the periods before and after the fiscal war. The other model allows to analyze changes in the growth rate of the variables between the periods. Estimates show that the states evaluated, individually or in group, present significant changes in the growth rate in their share of the industrial GDP nationwide, compared to the São Paulo state, after the fiscal war augmentation. The same results do not seem to apply to employment creation, that is, there were not changes in the employment rate in the industrial sector and in the ICMS revenue.
\end{abstract}

Keywords: fiscal war, federalism, economic development, tax policy, industrial concentration.

JEL classification: H20.

* Artigo derivado de tese de doutorado intitulada Guerra Fiscal: uma avaliação com base no PIB, nas receitas de ICMS e na geração de empregos, comparando Estados participantes e não participantes, agraciada com o premio CNI de Economia/2008. O autor gostaria de agradecer a Rodolfo Hoffmann e Márcia Regina Gabardo Câmara pelas preciosas sugestões.

$\S$ Professor do Departamento de Economia da Universidade Estadual de Londrina. Doutor pela Escola Superior de Agricultura Luiz de Queiroz - ESALQ - USP. Endereço para contato: Rua das Garças, n. 411 - Conj. Violim - Londrina - PR. Cep: 86084760. E-mail: sidnei@uel.br.

Recebido em janeiro de 2008. Aceito para publicação em julho de 2008. 


\section{INTRODUÇÃO}

Com a Constituição de 1988, logrou êxito um movimento em prol da maior autonomia fiscal dos Estados e municípios. Na busca pelos investimentos privados, estas Unidades Federativas (UF) estimularam as empresas a efetuarem o que se pode chamar de "leilão" para definir o Estado e o município que iria sediar suas novas plantas industriais. Este leilão foi vencido por quem ofereceu o maior pacote de benefícios à empresa. Estes benefícios vão desde a isenção, ou postergação nos recolhimentos do ICMS, ou do Imposto sobre Serviços (ISS), até a doação de terrenos, infra-estrutura e financiamentos de longo prazo.

Esta disputa entre os entes da Federação foi apelidada de "guerra fiscal" e é assim chamada por ter como instrumento de negociação a arrecadação futura de tributos, normalmente, o ICMS para os Estados e o ISS para os municípios. Não está pautada apenas em questões fiscais, mas também contempla benefícios financeiros. No cenário nacional, passou a ter destaque a partir da abertura comercial e da estabilidade econômica, e ganhou notoriedade com a concessão de um amplo conjunto de vantagens e benefícios, principalmente para o setor automobilístico. Seus impactos podem gerar conseqüências positivas e negativas; pela ótica do administrador público, os aspectos positivos seriam a geração de empregos e renda, o crescimento do PIB local, bem como da receita tributária futura. Os ônus seriam a desarmonia entre os entes federados e a perda de receita presente, que poderá não ser compensada no futuro, pois as empresas poderão migrar novamente para outros Estados, após o período de carência, ou seja, antes de o Estado recuperar em sua totalidade os recursos aplicados.

Os Estados avaliados foram Paraná, Rio Grande do Sul, Rio de Janeiro, Bahia, Ceará, Goiás, Mato Grosso, Mato Grosso do Sul, Minas Gerais, Espírito Santo e Santa Catarina, que são comparados ao Estado de São Paulo, que não entrou na disputa ou que, de certo modo, concedeu menos benefícios às empresas.

As variáveis utilizadas para a análise foram a participação porcentual de cada Estado na arrecadação do ICMS, na geração de empregos na indústria de transformação e nos demais setores, no PIB industrial, do comércio, serviços e agrícola. Para avaliar os possiveis efeitos da disputa tributária nestas variáveis, foram utilizados dois modelos econométricos, sendo um deles o de "diferenças em diferenças", que capta alterações comparativas das variáveis, entre o Estado que não participou da guerra (São Paulo) e os demais. O outro modelo consiste no ajuste de poligonais que permite identificar mudanças de tendência em diversas variáveis econômicas, comparando Estados nos períodos anteriores e posteriores à deflagração da guerra fiscal.

O estudo está estruturado em quatro partes, incluindo esta introdução. A segunda seção do trabalho apresenta uma discussão sobre o sistema federalista, as vantagens e desvantagens da descentralização tributária, as dificuldades em harmonizar os conflitos distributivos, bem como suas formas e características. Desenvolve-se também, nesta seção, uma simulação comparativa dos custos de um determinado produto, para uma empresa beneficiada tributariamente, em 
relação a uma não beneficiada. A terceira seção destina-se à análise empírica, comparando-se os Estados que concederam benefícios com o que não concedeu. A seção final foi reservada às considerações finais.

\section{TEORIA DO FEDERALISMO FISCAL, DA DESCENTRALIZAÇÃO FISCAL E DA COM- PETIÇÃO TRIBUTÁRIA}

\subsection{Guerra fiscal no Brasil}

Os Estados e as regiões brasileiras, ao longo do século XX, procuraram atrair investimentos geradores de emprego, produção, renda e crescimento econômico. Existem registros de disputas fiscais entre Estados desde a década de 1920. Na década de 1970, grande parte dos investimentos foram executados ou, pelo menos, direcionados pelo governo central para as regiões Norte e Nordeste do País. (SUZIGAN; FURTADO, 2006) No início da década de 1980, surge um movimento que busca o fortalecimento dos Estados e municípios, alcançando êxito na Constituição de 1988. Houve, com isto, transferência de maior fatia do bolo tributário e, conseqüentemente, maior autonomia para as UF legislarem sobre suas fontes de receita.

A maior liberdade fiscal foi um dos elementos que propiciou o desenvolvimento e o acirramento da chamada "guerra fiscal", que é um termo pejorativo encontrado na literatura para definir a competição tributária (HILLBRECHT, 1997; VARSANO, 1997). Por "guerra fiscal” entende-se a disputa entre as UF para atrair à sua esfera de domínio investimentos e/ou receita tributária oriundos de outros Estados. Esta prática se dá com a concessão de benefícios fiscais, financeiros e de infra-estrutura às empresas interessadas em investir ou transferir seus investimentos para o Estado que concede o benefício. A guerra é chamada de fiscal por estar centrada no jogo com a receita e a arrecadação futura de tributos, geralmente o ICMS (ARBIX, 2001). A guerra fiscal pode ser entendida como um típico comportamento de rent seeking, onde a disputa por novas rendas dissipa o valor da renda que se pretende obter (DEBACO; JORGE NETO, 1998).

Ao longo do tempo, os Estados foram se aprimorando na tentativa de atrair novos investimentos e desenvolveram outras formas de benefícios às empresas. De acordo com Alves (2001) e Perius (2002), os incentivos podem ser classificados em três tipos:

- Tipo 1 - Concessões prévias para o início da atividade produtiva: doação de terrenos, obras, facilidades de infra-estrutura e outras formas de dispêndio financeiro que geram benefícios parciais ou totais para a empresa.

- Tipo 2 - Benefícios creditícios associados ao investimento inicial e à operação produtiva: formas diversas de crédito para capital fixo ou de giro. O crédito pode ser oferecido pelo governo estadual, antes do início das operações da empresa, de uma só vez, ou em várias 
parcelas, ao longo do processo de implantação e/ou operação. Os financiamentos são ofertados pelas instituições bancárias de investimento, com recursos de fundos estaduais ou de programas de desenvolvimento regional.

- Tipo 3 - Benefícios tributários relacionados à operação produtiva: a renúncia fiscal pode se dar por meio da redução ou postergação de recolhimento ou, ainda, pela isenção de impostos.

O fenômeno guerra fiscal abrange políticas públicas pautadas em benefícios fiscais, financeiros e creditícios, que buscam atrair desenvolvimento para um Estado em detrimento de outras UF. Estas ações mostram que, enquanto um Estado se beneficia, gera algum prejuízo para outro, evidenciando, assim, que a guerra fiscal não é Ótimo de Pareto. ${ }^{2}$

Esta "Guerra" gera conflitos na Federação. No curto prazo, o Estado que deflagra a guerra se beneficia. No longo prazo, a generalização do conflito faz com que os ganhos iniciais desapareçam, pois os incentivos fiscais perdem o seu poder de estímulo e se transformam em meras renúncias de arrecadação (FERREIRA, 2000, p. 1); além disto, os Estados que mais perderão serão os mais pobres, que, curiosamente, são os que mais concedem incentivos, uma vez que, paralelo ao desenvolvimento atraído para o seu território, desencadeia-se a contrapartida natural, ou seja, o crescimento das demandas por serviços públicos, tais como: educação, saúde, transporte, segurança, saneamento básico, entre outras despesas provenientes do crescimento populacional e da elevação da renda per capita (LENGRUBER, 1999).

As justificativas para tal prática, sob a ótica do administrador público, são: a geração de empregos e renda; o aumento do valor adicionado ao longo das cadeias produtivas, devido à maior transformação industrial e, ainda, o aumento da receita tributária futura (HULTEN; SCHWAB, 1997).

\subsection{As formas de disputa tributária}

A disputa tributária pode ser classificada em vertical ou horizontal. É denominada vertical aquela em que a União se contrapõe às UF. Com a ampliação, em 1988, do bolo tributário recebido por Estados e municípios, sem a transferência dos encargos nas mesmas proporções, agrava-se a crise fiscal pela qual a União vinha passando desde o início dos anos de 1980. Esta prioriza, a partir daí, sua arrecadação por meio das contribuições sociais, que não estão sujeitas

1 Para a concessão de alguns benefícios tributários ligados ao ICMS, como a isenção de tributos, a proposta deve ser aprovada pelo CONFAZ (Conselho Nacional de Política Fazendária), órgão que reúne os secretários da Fazenda dos Estados e do Distrito Federal, e que regulamenta a concessão destes benefícios. Como estes benefícios tendem a ser rejeitados pelos membros dos outros Estados, foram desenvolvidas, para mascarar as isenções fiscais, práticas de benefícios que proporcionam resultados semelhantes, mas que não são classificadas como benefícios fiscais. O benefício mais utilizado são os financiamentos de longo prazo, que, na prática, são recursos públicos transferidos para as empresas, os quais equivalem a uma proporção dos valores pagos de ICMS pela empresa beneficiada. Em alguns casos, os Estados não cobram juros ou correção monetária pelo financiamento.

2 Segundo Varian (1994, p. 33), uma situação econômica é dita eficiente de Pareto se não existir nenhuma forma de melhorar a situação de alguma pessoa sem piorar a de outra. 
a transferências. Portanto, a competição tributária vertical nada mais é do que uma disputa por tributos entre o poder central e as unidades federadas (PRADO; CAVALCANTI, 1998).

A Competição Tributária Horizontal se desenvolve entre governos de mesmo nível hierárquico. No caso brasileiro, ocorre entre Estados, via isenções do ICMS, e entre municípios, via isenções do ISS, do IPTU e de outras taxas municipais, além de cessão ou doação de terrenos. Pode ter como finalidade estimular o desenvolvimento econômico ou simplesmente ampliar a receita tributária. Para exemplificar estes casos, suponha-se que um município conceda redução ou isenção no ISS para um hotel que venha instalar-se na cidade; a justificativa para tal seria o desenvolvimento local e a geração de empregos e renda, que poderia perfeitamente ocorrer.

Já para avaliar a disputa por tributos, considere-se o exemplo de uma empresa que presta serviços de vigilância, sediada em uma metrópole e tributada com uma alíquota de 5\% de ISS e cujos clientes também estão sediados nesta metrópole. Admitindo-se que uma cidade vizinha, normalmente de pequeno porte, estipule sua alíquota em $0,5 \%$ para esta atividade, a empresa terá grandes incentivos para deslocar a sua sede para a cidade vizinha, em função da redução de $4,5 \%$ em seus custos fiscais.

O município vizinho realiza um excelente negócio, passando a arrecadar uma alíquota de 0,5\% sobre o valor dos serviços prestados, em detrimento da metópole que perde toda a receita. A empresa, em alguns casos, não necessita deslocar-se para a cidade vizinha, mantendo apenas um endereço para correspondência.

Para exemplificar a disputa entre os Estados, vamos supor que uma empresa de alimentos transfira sua planta para um Estado com vocação agrícola. O Estado é um produtor de insumos para essa indústria, o que sugere que a transferência não se deu exclusivamente devido aos benefícios fiscais. Outros critérios técnicos, como disponibilidade de insumos e mão-de-obra, também foram considerados. Por fim, o Estado certamente será beneficiado por estimular a geração de empregos e renda.

Como exemplo da má utilização da autonomia fiscal, pode-se citar o caso definido pelo Dr. Clovis Panzarini ${ }^{3}$ como "pirataria fiscal”, descrito em Sapienza et al. (1998, p. 41). O Estado do Espírito Santo, por meio do Fundo para o Desenvolvimento das Atividades Portuárias (FUNDAP), propicia ao importador que operar pelo Porto de Vitória um financiamento do ICMS equivalente a $70 \%$ do imposto devido com a venda do bem importado, por 20 anos, com cinco anos de carência.

Em 1994, o Brasil importou cerca de 300 mil automóveis, 1990\% dos quais entraram pelo Porto de Vitória. Desses, $45 \%$ foram destinados ao Estado de São Paulo. Na prática, criou-se um instrumento legal para arrecadar $30 \%$ do imposto gerado na operação, pois prorrogar por 25 anos uma receita, sem corrigi-la, é praticamente abrir mão dela ou, pelo menos, de boa parte

3 Dr. Clovis Panzarini foi coordenador da Administração Tributária da Secretaria da Fazenda do Estado de São Paulo. 
dela, principalmente se houver elevados índices de inflação no período. Dos $30 \%$ do imposto devido pela importadora e efetivamente recolhido aos cofres estaduais, $75 \%$ fica para o Estado do Espírito Santo e $25 \%$ é repassado para a prefeitura de Vitória.

Sem os incentivos tributários, provavelmente, a maior parte dos automóveis seria desembarcada no porto de Santos, e os tributos recolhidos, na sua íntegra, para o Estado de São Paulo.

\subsection{Distorções na eficiência alocativa}

Com a disputa para atrair novos investimentos, os Estados estimulam as empresas interessadas em se transferir para outro Estado a efetuarem verdadeiros leilões entre as UF previamente escolhidas. De acordo com pesquisa da CNI/Cepal, ${ }^{4}$ os incentivos fiscais possuem pesos menores na tomada de decisão pela mudança. Isto mostra que as empresas já se encontram estimuladas para o deslocamento, e que o incentivo fiscal é apenas um plus na busca pela redução de custos, conforme mostram Prado e Cavalcanti (2000, p. 31) na Tabela 1.

\section{Tabela 1 - Fatores determinantes para instalação de plantas produtivas}

\begin{tabular}{lc}
\hline FATOR & RESPOSTAS RELEVANTES (\%) \\
\hline Custo de Mão-de-Obra & 41,5 \\
Benefícios Fiscais & 57,3 \\
Sindicalismo Atuante na Região & 24,4 \\
Saturação Espacial & 14,6 \\
Vantagens Locacionais Específicas & 39,0 \\
Proximidade do Mercado & 57,3 \\
\hline
\end{tabular}

Fonte: Prado e Cavalcanti, 2000 - Pesquisa CNI/CEPAl.

Se forem levados em consideração os fatores mencionados na Tabela 1, as empresas transferem suas plantas a outros Estados visando alocação eficiente de recursos, havendo perda apenas na receita tributária do Estado de origem. Caso se deslocassem sem levar em consideração a eficiência global na alocação dos recursos, ou seja, dando peso indevido ao incentivo fiscal, estariam operando com ineficiência econômica. O relato disto encontra-se em Tyler (1998), a partir das conclusões dos estudos do Banco Mundial a respeito da política de incentivos fiscais do governo cearense:

1) Apenas grandes empresas recebem incentivos fiscais em função do elevado custo em buscar e obter os mesmos.

2) As novas plantas tendem a ter uma relação Capital/Trabalho elevada.

4 A Pesquisa da CNI/Cepal foi efetuada em 730 empresas brasileiras de porte médio e grande (média de 950 empregados), versando sobre características e determinantes do investimento na indústria entre 1995 e 1997. 
3) Os incentivos de ICMS tendem a discriminar empresas domésticas, uma vez que a idéia é atrair novas empresas para o Estado, estimulando, com isto, a migração das empresas domésticas para Estados vizinhos.

4) O esquema parece canalizar investimentos em atividades lobistas em detrimento dos investimentos em modernização das plantas.

5) Distorções locacionais: a escolha da localização em função dos incentivos, e não da eficiência na utilização dos fatores de produção disponíveis, gera um custo econômico invisível pela perda de produtividade. Este custo será assimilado pelo contribuinte local, seja pelo aumento dos impostos ou pela redução na oferta de bens públicos.

6) Distorções dos gastos públicos: os dispêndios das UF são concentrados em infra-estrutura em detrimento dos gastos sociais.

7) Distorções das vantagens comparativas: um exemplo seria o Estado do Piauí isentar uma fábrica de fibra ótica e aumentar o ICMS dos produtores de óleo de babaçu.

Em termos gerais, a ineficiência econômica é o resultado de uma ação individual que afeta, diretamente, o nível de satisfação de outro agente. Quando na escolha de um comportamento que consideram ótimo, indivíduos não internalizam o "mal” que causam ao vizinho, o resultado da ação não será ótimo do ponto de vista social (embora possa ser do ponto de vista individual). Dado que a decisão pela alíquota de ICMS ótima não leva em conta o prejuízo que sua imposição gerará no Estado vizinho, esta alíquota será fixada em nível diferente do que seria eficiente. Isso implica, dentre outros efeitos, uma oferta de bens públicos abaixo do socialmente desejável.

A experiência internacional é rica em casos de guerra fiscal, que não diferem, significativamente, da situação brasileira. Break (apud FERREIRA, 2000) deixa isso claro no seguinte depoimento sobre o caso dos Estados Unidos: "O problema é que Estados e governos locais têm engajado há algum tempo em crescente competição por novos negócios.... Competição tributária, em resumo, tende a produzir um geralmente baixo nível de esforço tributário local ou uma estrutura tributária estadual com fortes elementos regressivos".

A regressividade na estrutura tributária decorre do fato de que Estados tentam atrair fatores móveis por meio de redução da alíquota. Ao mesmo tempo, para manter o orçamento proximamente equilibrado, sobretaxam os fatores menos móveis. Contudo, capital é, geralmente, mais volátil do que trabalho, especialmente quando se trata de trabalho menos qualificado.

\subsection{Simulação do efeito de vantagem fiscal sobre o custo médio de uma firma}

Os governos em todo o mundo monitoram os processos de fusões e aquisições pelas grandes empresas, com a finalidade de evitar a formação de monopólios ou oligopólios. O processo de concentração industrial pode ser maléfico ao consumidor, quando a produção for concentra- 
da em poucas firmas e as firmas usufruírem do seu poder de mercado, elevando sensivelmente as margens de lucro, dadas as barreiras à entrada existentes no mercado.

Nogueira e Jorge Neto (1998) avaliaram os impactos da entrada no mercado de uma nova firma, gozando de benefícios fiscais, em detrimento de suas concorrentes, sem tais benefícios. Os autores chamam a atenção para o risco que a sociedade está sujeita quando o governo adota este comportamento sem conhecer as reais características do mercado, alterando as vantagens comparativas de uma empresa em detrimento de outra.

Neste sentido, de forma a complementar o arcabouço teórico sobre o tema, buscou-se avaliar comparativamente duas empresas hipotéticas. Uma gozando de benefícios fiscais, e a outra não. A hipótese aqui levantada é que a interferência do Estado, por meio de benefícios fiscais, poderá alterar a estrutura do mercado, a ponto de induzir a concentração industrial entre as firmas.

Para avaliar a perda de competitividade gerada pela guerra fiscal, foram simuladas duas empresas hipotéticas $A$ e $B$, atuando no mesmo mercado, com produtos homogêneos. A empresa $A$, localizada no Estado $X$, beneficia-se de um programa de favorecimento fiscal. Seus recolhimentos de ICMS serão postergados por $20^{5}$ anos, e os pagamentos serão feitos sem juros e sem correção monetária, integralmente ao final do vigésimo ano. A empresa $B$, localizada no Estado $Y$, não recebe nenhum benefício e, portanto, deve recolher aos cofres estaduais o ICMS devido mensalmente.

Para simplificar os cálculos comparativos, presume-se que as duas empresas gerem o mesmo montante de recolhimento de ICMS, ou seja, o mesmo custo tributário. Por meio de cálculos financeiros, atualizou-se o total pago ao longo do tempo pelas duas empresas, para o valor presente, sendo possível identificar o verdadeiro custo tributário das duas empresas simuladas; utilizou-se uma taxa de juros de $6 \%$ a.a., equivalente à remuneração da poupança e uma taxa de inflação estimada em $5 \%$ a.a. Foi obtido um custo monetário de 11,3\% ao ano, o que representou aproximadamente $0,8962 \%$ ao mês.

Segundo informações da Secretaria do Tesouro Nacional, STN, no ano de 2005, a receita de ICMS totalizou 7,99\% do PIB brasileiro. Admitiu-se que, do total produzido pelas empresas, estas deveriam recolher este porcentual sobre a comercialização de seus produtos.

Admitiu-se que cada empresa gerou o mesmo débito do ICMS, estipulado em R $\$ 1.000,00$. A empresa $B$ deveria recolher no início do mês seguinte ao faturamento. A empresa $A$, por sua vez, iria recolher $\mathrm{R} \$ 240.000,00$ no final do vigésimo ano. Calculando-se o valor presente para as duas empresas, concluiu-se que a empresa $A$ deveria recolher $\mathrm{R} \$ 28.203,00$ e a empresa $B$, $\mathrm{R} \$ 98.475,00$.

5 O prazo de 20 anos foi definido com base em programas de desenvolvimento industrial. Para maiores detalhes, ver Carvalho e Oliveira (2003) e Sapienza (1998). 
A empresa $A$ recolheu apenas $28,64 \%$ do valor recolhido pela empresa $B$. Como o ICMS representou $7,99 \%$ do custo do produto, isto gerou uma redução no custo da empresa $A$ de $5,70 \%$, em relação a sua concorrente, conforme Tabela 2.

Tabela 2 - Diferencial do custo do produto

\begin{tabular}{lcc}
\hline Base inicial $R \$ 1.000,00 /$ mês & Empresa $A$ & Empresa $B$ \\
\hline Total recolhido em valor presente & $\mathrm{R} \$ 28.203,00$ & $\mathrm{R} \$ 98.475,00$ \\
Porcentagem \% & 28,64 & 100 \\
Diferencial \% & 71,36 & \\
Diferencial do custo no produto & $5,70 \%$ & \\
$(71,36 \%$ X ICMS 7,99\%) & & \\
\hline
\end{tabular}

Portanto, a guerra fiscal poderá alterar a estrutura concorrencial das empresas, estimulando o processo de concentração e, como conseqüência, incentivar o desenvolvimento de grupos oligopolistas.

\section{ANÁLISE EMPÍRICA DA RENÚNCIA FISCAL}

\subsection{Dados e metodologia}

As variáveis usadas nesta pesquisa, e descritas a seguir, tiveram como fonte de informações o Instituto de Pesquisa Econômica Aplicada (IPEADATA), a Secretaria do Tesouro Nacional (STN), o Ministério do Trabalho e Emprego (MTE) e o Instituto Brasileiro de Geografia e Estatística (IBGE). O período avaliado foi a partir do início da década de 1990 para todas as variáveis.

Admite-se, nesta pesquisa, que a guerra fiscal se fortaleceu a partir da segunda metade da década de 1990. Este marco foi determinado em função desta disputa estar intimamente ligada aos investimentos estrangeiros no Brasil. Segundo Nascimento (2002), os investimentos externos, na segunda metade da década de 1990, foram 18,41 vezes superiores, em média, aos da primeira metade. Assim, como não existe um ano específico de referência para medir as alterações econômicas oriundas da disputa, optou-se pelas avaliações gráficas, que indicaram 1998 como o 
ano mais apropriado para as mudanças de tendência nas variáveis, com excecão da arrecadação do ICMS, para a qual foi utilizado o ano de 1997.

Os dados referem-se aos Estados de São Paulo, Paraná, Ceará, Bahia, Rio Grande do Sul, Rio de Janeiro, Santa Catarina, Minas Gerais, Espírito Santo, Goiás, Mato Grosso e Mato Grosso do Sul. A seleção destes Estados foi norteada por dois motivos: o primeiro é que São Paulo, Paraná, Rio Grande do Sul, Rio de Janeiro, Santa Catarina e Minas Gerais representavam 81,6\% da produção brasilleira em 1990. Portanto, alterações significativas em suas participações na produção indicam um fenômeno importante para a economia nacional. Os Estados do Ceará, Bahia, Espírito Santo, Goiás, Mato Grosso e Mato Grosso do Sul foram incluídos por serem recorrentemente citados na literatura como participantes ativos da guerra fiscal. ${ }^{6}$ Os demais Estados não foram considerados por terem pouca relevância na literatura sobre o tema, bem como baixa representação no PIB e, portanto, pequenas mudanças do seu parque industrial podem significar grandes alterações relativas nas variáveis analisadas, mas de pouca importância para a pesquisa.

As variáveis utilizadas foram: Arrecadação de ICMS, o Produto Interno Bruto e a Geração de Empregos no Setor Industrial. O enfoque da pesquisa deu-se em torno do setor da indústria de transformação. Tal procedimento foi embasado em uma pesquisa do Instituto Brasileiro de Geografia e Estatística (IBGE) sobre o Perfil dos municípios brasileiros - gestão pública 2006 (IBGE, 2007), a qual indicou que, entre 2004 e 2005, 68\% dos municípios concederam benefícios para o setor industrial, contra $43 \%$ para o comércio e serviços, $12 \%$ para o turismo, esporte e lazer e apenas $14 \%$ para o setor agrário. Além disto, o setor industrial é o que possui maior flexibilidade migratória em relação aos demais, o que lhe concede maior poder de negociação com os Estados e municípios.

\subsubsection{A arrecadação do ICMS}

Os dados da arrecadação do ICMS nos Estados foram obtidos no IPEADATA, oriundos da Secretaria do Tesouro Nacional (STN). O total desta receita representa a agregação dos setores primário, secundário e terciário. Os anos analisados vão de 1990 a 1996, considerado como período anterior à guerra fiscal, e de 1997 a 2005, posterior à disputa. Os governos, com o intuito de justificar as isenções concedidas às empresas, alegam que a economia será estimulada, o que, conseqüentemente, aumentará a receita dos Estados. Sendo assim, acréscimos na arrecadação do ICMS, no segundo período, deverão refletir efeitos do conflito tributário.

\subsubsection{O Produto Interno Bruto - PIB}

As informação do PIB por setor foram obtidas no IPEADATA, originárias do IBGE. Estão desagregadas em PIB da indústria, do comércio, serviços e do setor agrícola. Com estas desagregações é possivel fazer comparações entre os setores, o que pode indicar políticas industriais

6 Ver Prado e Cavalcanti (1998), Ferreira (2000) e Lengruber (1999). 
mais ou menos eficientes. Os anos de 1990 a 1997 foram considerados anteriores ao conflito e, de 1998 a 2004, como o período de intensificação da guerra fiscal.

\subsubsection{Geração de empregos no setor da indústria de transformação}

Os dados da geração de novos postos de trabalho na indústria de transformação e nos demais setores foram obtidos no Ministério do Trabalho e Emprego, em seu registro administrativo denominado Relação Anual de Informações Sociais (RAIS) (BRASIL/MTE, 1990 - 2004). O período de 1990 a 1997 foi considerado anterior ao conflito, e o de 1998 a 2004 foi considerado posterior.

Os novos postos de trabalho na indústria de transformação deverão receber um impacto positivo a partir da ampliação ou atração de uma nova indústria, negativo quando da emigração desta.

As variáveis utilizadas foram transformadas de forma a representar a participação porcentual de cada Estado no total do País. Esta forma de apresentação dos dados representa com maior eficiência o comportamento de tendência de uma UF em relação a outra, que é o que se pretende captar.

Lembremos que o objetivo deste trabalho é verificar o comportamento das variáveis apresentadas, de forma a identificar alterações nas mesmas que possam ser associadas com a guerra fiscal. Para atingir tal objetivo, foram separados os Estados que concederam benefícios fiscais, denominados "Estado de tratamento", do Estado que não concedeu, ou o fez com menor intensidade (São Paulo), denominado "Estado de controle”. Também é possível comparar duas variáveis do mesmo Estado, considerando como resultado do tratamento a variável que deve ser mais afetada pela guerra fiscal e, como controle, a outra variável.

Foram adotados dois modelos econométricos, utilizando-se Mínimos Quadrados Ordinários (MQO) para as análises. O modelo 1, denominado de diferenças em diferenças, é apresentado, por exemplo, em Wooldridge (2001), e o modelo 2 utiliza variáveis binárias para ajustes de poligonais. ${ }^{7}$

O modelo de diferenças em diferenças busca contornar o fato de não haver informações, neste caso, sobre os Estados tratados, caso eles não tivessem sido tratados, ou seja, qual seria a situação do Estado que entrou na guerra, caso ele não participasse dela. Observou-se o comportamento das variáveis nos Estados que concederam benefícios, em relação ao Estado que não concedeu, ou seja, São Paulo. Logo, o problema empírico concentra-se na estimação do contrafactual da política, ou melhor, quais seriam os resultados dos Estados tratados, caso os benefícios não tivessem sido concedidos.

7 Sobre o uso de variáveis binárias para ajuste de poligonais, ver, por exemplo, Hoffmann (2006) 
Quando as comparações são feitas entre duas variáveis diferentes no mesmo Estado, os objetivos são semelhantes, ou seja, comparar a relação existente entre estas, em dois períodos distintos.

O modelo 1 inclui uma variável binária de tratamento, uma variável binária de período e a interação entre as duas. A binária de tratamento, indicada por $S_{i}$, será igual a zero para São Paulo e igual a um para o outro Estado, que representa o grupo de tratamento.

A binária que define o período, indicada por $P_{i}$, é igual a zero antes da guerra fiscal, e é igual a um no segundo período, quando os Estados, teoricamente, já estão com suas novas plantas industriais em pleno funcionamento, permitindo captar mudanças de comportamento das variáveis em relação ao período anterior.

A binária de interação, ou seja, o produto $S_{i} P_{i}$ será igual a zero nos dois períodos em São Paulo e, para o outro Estado, será igual a zero no primeiro período e igual a um no segundo período.

Logo, a estimação dos efeitos da alteração na política fiscal pode ser obtida a partir do seguinte modelo de regressão linear múltipla (modelo 1):

$$
Y_{i}=\alpha+\beta_{1} S_{i}+\beta_{2} P_{i}+\beta_{3} S_{i} P_{i}+u_{i}
$$

em que

$Y_{i}$ é a participação porcentual de cada Estado no conjunto dos Estados brasileiros.

$S_{i}$ representa a binária definida como zero para o grupo de controle e um para o grupo de tratamento.

$P_{i}$ representa a binária que é igual a zero no primeiro período e um no segundo.

$\alpha, \beta_{1}, \beta_{2}$ e $\beta_{3}$ são os parâmetros.

$u_{i}$ representa o erro aleatório.

$i$ indica um determinado ano.

A variável binária que indica o período $\left(P_{i}\right)$ capta fatores agregados que afetam $Y_{i}$ em cada momento, mas com o mesmo efeito nos dois grupos (tratamento e controle). Já a binária que indica o Estado $\left(S_{i}\right)$ capta possíveis diferenças entre os grupos. Assim, o coeficiente mais importante para a análise é o da interação $S_{i} P_{i}$, que mostra a mudança do primeiro para o segundo período, na diferença de nível de $Y_{i}$ entre os dois grupos.

O valor esperado de $Y_{i}$ nas quatro situações distintas será indicado por $Y_{k h}^{*}$, com $h$ indicando o período inicial $(h=0)$ ou final $(h=1)$ e $k$ indicando o grupo de controle $(k=0)$ ou o grupo de tratamento $(k=1)$. Verifica-se que: 
a) Valor esperado de $Y_{i}$ antes da guerra fiscal no grupo de controle: $Y_{00}^{*}=E\left(Y_{i} \mid S_{i}=0, P_{i}=0\right)=\alpha$.

b) Valor esperado de $Y_{i}$ após a guerra fiscal no grupo de controle: $Y_{01}^{*}=E\left(Y_{i} \mid S_{i}=0, P_{i}=1\right)=\alpha+\beta_{2}$.

c) Valor esperado de $Y_{i}$ antes da guerra fiscal no grupo de tratamento: $Y_{10}^{*}=E\left(Y_{i} \mid S_{i}=1, P_{i}=0\right)=$ $=\alpha+\beta_{1}$.

d) Valor esperado de $Y_{i}$ após a guerra fiscal no grupo de tratamento: $Y_{11}^{*}=E\left(Y_{i} \mid S_{i}=1, P_{i}=1\right)=$ $=\alpha+\beta_{1}+\beta_{2}+\beta_{3}$.

$\mathrm{O}$ valor de $\beta_{3}$ mostra em quanto o crescimento entre os dois períodos no grupo de tratamento difere do crescimento no grupo de controle. Alternativamente, pode-se dizer que $\beta_{3}$ mostra em quanto a diferença entre grupos se altera do primeiro para o segundo período.

A principal e grave limitação do modelo 1 é não ter instrumentos para captar possíveis tendências anteriores aos dois períodos comparados. Tal fato pode comprometer as análises ${ }^{8}$ (ANGRIST; KRUEGER, 1998). A utilização do modelo 2 se fez necessária para detectar estas mudanças na tendência das variáveis entre os dois períodos e os dois grupos analisados.

Modelo de regressão linear múltipla (modelo 2):

$$
Y_{i}=\alpha_{0}+\beta_{0} t+\delta_{0} P_{i}(t-\theta)+\alpha_{1} S_{i}+\beta_{1} t S_{i}+\delta_{1} P_{i}(t-\theta) S_{i}+u_{i}
$$

em que

$Y_{i}$ é a participação porcentual de cada Estado no conjunto dos Estados brasileiros.

$P_{i}$ representa a binária que é igual a zero no primeiro período e um no segundo.

$t$ representa uma variável de tendência.

$\theta$ representa a abscissa do vértice que, neste modelo, é o ano que delimita o período anterior e o posterior à guerra fiscal.

$S_{i}$ representa a binária definida como zero para o grupo de controle e um para o grupo de tratamento.

$\alpha_{0}, \alpha_{1}, \beta_{0}, \beta_{1}, \delta_{0}$ e $\delta_{1}$ são os parâmetros.

$u_{i}$ representa o erro aleatório.

$i$ indica um determinado ano.

Nesse modelo verifica-se que o crescimento anual do valor esperado de $Y_{i}$ é igual a:

8 Como exemplo, digamos que o Estado de São Paulo já passava por um processo de desconcentração industrial antes da guerra fiscal, e o Estado da Bahia estava em um processo de crescimento do seu parque industrial, também antes da guerra fiscal. Assim, os resultados do modelo 1 indicarão que a Bahia consegue melhor desempenho que São Paulo após a guerra fiscal, sendo que isto já ocorria independentemente da guerra fiscal. 
a) $\beta_{0}$, no grupo de controle, antes da mudança estrutural.

b) $\beta_{0}+\delta_{0}$, no grupo de controle, após a mudança estrutural.

c) $\beta_{0}+\beta_{1}$, no grupo de tratamento, antes da mudança estrutural.

d) $\beta_{0}+\delta_{0}+\beta_{1}+\delta_{1}$, no grupo de tratamento, após a mudança estrutural.

Note-se que essas expressões representam taxas aritméticas de crescimento anual de $Y_{i}$. Uma vez que $Y_{i}$ é uma participação porcentual, essas taxas aritméticas de crescimento são expressas em pontos porcentuais (p.p.) por ano.

Pode-se dizer que $\delta_{0}$ representa a aceleração do crescimento no grupo de controle e $\delta_{0}+\delta_{1}$ representa a aceleração do crescimento no grupo de tratamento. Então, o valor $\delta_{1}$ indica em quanto a aceleração no crescimento de $Y_{i}$ no grupo de tratamento difere da aceleração no crescimento do grupo de controle.

Ao ajustar os modelos 1 e 2, em geral considerou-se o Estado de São Paulo como controle e um outro Estado como tratamento. Porém, os modelos também foram estimados considerando como tratamento o valor total para os outros Estados (BA, CE, PR, RJ, RS, SC, ES, GO, MG, MS e MT), denominado como TOTAL UF. Esta técnica visa avaliar o conjunto desses Estados em relação ao Estado de controle (SP), e capta possíveis variações no conjunto dos Estados que não foram identificadas individualmente.

Os modelos de regressão também podem ser usados para comparar o comportamento de duas variáveis em um mesmo Estado, com uma das variáveis fazendo o papel de "controle" e a outra fazendo o papel de "tratamento". Nesse caso, a binária $S_{i}$ é igual a zero quando $Y_{i}$ representar a primeira variável (“controle”), e é igual a 1 quando $Y_{i}$ representar a segunda variável ("tratamento"). Esse modelo pode ser usado, por exemplo, para comparar o crescimento do PIB industrial na Bahia com o crescimento do PIB no conjunto dos demais setores no mesmo Estado. Admitindo que os incentivos fiscais são orientados principalmente para atrair empresas industriais, o PIB industrial representa o resultado do "tratamento", e o PIB no conjunto dos demais setores representa o "controle".

\subsection{Avaliação dos resultados}

Os resultados mais importantes obtidos com os modelos 1 e 2 estão descritos nas Tabelas de 3 a 5, todos os resultados apresentaram o coeficiente de correlação $\left(R^{2}\right)$ acima de 0,70 e as estatistícas $F$ foram significativas. No modelo 1, apresenta-se a estimativa do parâmetro $\beta_{3}$, da variável de interação $S_{i} P_{i}$, que identifica a diferença na taxa aritmética de crescimento da participação porcentual, no grupo de tratamento, em relação ao grupo de controle, entre os dois períodos avaliados. 
Por sua vez, o modelo 2 apresenta a estimativa do parâmetro $\delta_{1}$, da variável $P_{i}(t-\theta) S_{i}$, mostrando em quanto a diferença entre as taxas aritméticas de crescimento da participação porcentual nos grupos de tratamento e controle supera, após a mudança de estrutura, a mesma diferença no período anterior à mudança. Alguns gráficos serão apresentados para efeito de ilustração das tabelas.

A Tabela 3 mostra os resultados obtidos com a variável PIB na indústria, sendo que São Paulo representa o grupo de controle e os outros Estados analisados, ou a soma destes (TOTAL UF), o grupo de tratamento.

Os resultados do modelo 1 indicam que o crescimento da participação porcentual no PIB industrial do Brasil, em todos os Estados, é superior ao de São Paulo. Por exemplo, na Bahia, o coeficiente $\beta_{3}=6,33$ indica que a participação porcentual do PIB industrial do Estado baiano cresceu em média 6,33 pontos porcentuais (p.p.) acima do ocorrido em São Paulo entre os períodos 1990-1997 e 1998-2004. Para os demais Estados, o crescimento entre os dois períodos superou o de São Paulo em: CE, 5,70; PR, 5,32; RJ, 9,23; RS, 4,79; SC, 6,05; ES, 5,66; GO, 6,09; MG, 5,65; MS, 5,71, e MT, 5,76 p.p.

Os resultados do modelo 2 mostram que a aceleração na taxa anual de crescimento do PIB industrial nos Estados, no segundo período, é significativamente superior à aceleração da taxa em São Paulo, com exceção do Ceará e de Minas Gerais. Como exemplo, no Estado da Bahia, o parâmetro $\delta_{1}$ mostra que a aceleração média anual na taxa de crescimento da participação porcentual do PIB industrial superou a aceleração em São Paulo em 0,49 p.p. por ano. Nos demais Estados, a aceleração superou a de São Paulo em: PR, 0,33; RJ, 1,14; RS, 0,34; SC, 0,30; ES, 0,32; GO, 0,37; MS, 0,26, e MT, 0,30 p.p. por ano.

Os resultados com a variável TOTAL UF mostram, no modelo 1, crescimento na participação do PIB industrial de 10,16 p.p. acima do ocorrido em São Paulo.

Já no modelo 2, a aceleração média da taxa de crescimento do TOTAL UF, a partir de 1997, superou a de São Paulo em 0,56 p.p. por ano. Observa-se que a estimativa de $\delta_{1}$ não é estatisticamente diferente de zero para CE e MG. Apesar disso, verifica-se que a estimativa de $\delta_{1}$ para o TOTAL UF (0,56 p.p. por ano) é positiva e significativa. O Gráfico 1 mostra o mesmo fenômeno, ou seja, o crescimento do PIB industrial no TOTAL UF e uma redução da participação de São Paulo, que se intensifica a partir de 1988.

Cabe considerar a hipótese de que o fraco desempenho do Estado paulista em relação aos demais seria ocasionado pela presença de um processo de desconcentração industrial motivado por problemas estruturais, inerentes aos grandes centros, e não pela disputa tributária entre os Estados. Partindo desta premissa, testou-se a presença de diferenças na tendência do PIB industrial no Estado de São Paulo, em relação ao PIB industrial da capital paulista. Admite-se que esta diferença esteja associada à saturação espacial, ao sindicalismo fortemente atuante e 
aos problemas no transporte, que fazem parte do cotidiano da capital paulista, e que não se apresentam, ou se apresentam com menor intensidade, nos demais municípios do Estado.

Para testar este fenômeno, foram utilizados os modelos 1 e 2. Os dados utilizados referemse aos anos de 1980, 1985, 1996, 1999 e de 2000 a 2004. ${ }^{9}$ Considerou-se até 1996 como período anterior à guerra fiscal e, a partir daí, o pós-guerra fiscal. Como grupo de controle, adotou-se o Estado de São Paulo e, como tratamento, a capital paulista.

No modelo 1, o parâmetro $\beta_{3}=4,53$ indica que a participação porcentual do PIB industrial da capital paulista cresceu, em média, 4,53 p.p. acima do crescimento da participação de São Paulo entre os anos de 1999 e 2004.

Os resultados do modelo 2 demonstram que a aceleração da taxa de crescimento no PIB industrial da capital, no segundo período, não é significativamente diferente da aceleração em São Paulo.

A avaliação do Gráfico 2 confirma não haver diferenças significativas de tendência no PIB industrial entre o Estado de São Paulo e sua capital, e que esta tendência se mostra decrescente desde 1980 .

Esta pesquisa não ignora o fato de que a saturação espacial, o desempenho sindicalista e os problemas no transporte possam ser determinantes para o desenvolvimento de um Estado. Em São Paulo, estes fatores parecem não ter influenciado no fraco desempenho do Estado em relação aos seus concorrentes. Esta conclusão reforça a hipótese de que a guerra fiscal foi o principal motivo para as mudanças ocorridas na década de 1990 na Federação brasileira.

Os governantes estaduais, para justificarem a sua adesão à guerra fiscal, afirmam que tal procedimento estimula aumentos na receita do ICMS. Este aumento, no curto prazo, seria fruto do efeito multiplicador, a partir da instalação de uma nova empresa no Estado, ou seja, o crescimento indireto desencadeado pela implantação de uma nova planta. No longo prazo, o crescimento da receita seria fruto do recolhimento do ICMS pela empresa, quando do término da postergação do recolhimento do tributo.

A Tabela 3 mostra também os resultados obtidos, analisando a participação porcentual de cada Estado na arrecadação do ICMS, sendo que São Paulo representa o grupo de controle, e um dos Estados, ou TOTAL UF, representa o grupo de tratamento. O objetivo é avaliar o comportamento da participação porcentual dos Estados em relação a São Paulo, na receita do ICMS.

No modelo 1, os resultados indicam que, em todos os Estados avaliados, inclusive o TOTAL UF, houve crescimento na taxa de participação do ICMS em comparação a São Paulo.

9 Para efetuar estes testes, foi necessária a obtenção do PIB industrial por município. Estes dados só estão disponíveis no IPEADATA, nos anos utilizados. 
Por exemplo, a participação da Bahia no ICMS no Brasil cresceu, em média, 3,03 p.p. acima do crescimento da participação do Estado paulista.

No modelo 2, os resultados sugerem que a aceleração da taxa de crescimento na receita de ICMS, em todos os Estados, superou a aceleração em São Paulo. Como exemplo, no Estado baiano, a aceleração média anual da taxa foi 0,82 p.p. superior à aceleração em São Paulo.

Analisando o modelo 2 com o TOTAL UF, o parâmetro $\delta_{1}=1,54$ indica que houve aceleração da taxa de crescimento do ICMS em comparação a São Paulo, o que pode ser confirmado no Gráfico 3.

A avaliação comparativa do PIB nos setores com as receitas de ICMS estão nos Gráficos 4 e 5, que mostram o comportamento das variáveis PIB industrial, a média do PIB nos setores comercial, de serviços e agrícola (PIB OUTROS) e a receita de ICMS, para o Estado de São Paulo e para os demais Estados avaliados TOTAL UF. No Gráfico 4, estas variáveis estão expressas na forma de participação porcentual em relação ao Brasil. No Gráfico 5, estão expressas adotando como base (valor igual a 100) o ano de 1990.

Percebe-se, nestes gráficos, que a receita de ICMS em São Paulo está correlacionada a sua base de tributação (PIB industrial e a média do PIB nos outros setores), ou seja, o PIB OUTROS cresce até 1998, o PIB industrial cai, e o ICMS se mantém relativamente estável neste período. A partir de 1998, a queda do PIB industrial se intensifica, o PIB OUTROS assume comportamento de queda e a receita de ICMS segue uma tendência intermediária.

A tendência do ICMS nos demais Estados TOTAL UF mostra correlação com sua base até 1994 e, a partir daí, sofre forte queda até 1997, desvinculando-se da sua base tributária, que mostra tendência de crescimento. A partir de 1997, o ICMS TOTAL UF retoma o comportamento crescente, porém, em níveis mais próximos do PIB OUTROS do que do PIB industrial.

Sendo assim, o ICMS em São Paulo se mostra intimamente ligado à base de tributação, ao passo que, nos demais Estados analisados, o crescimento do ICMS fica abaixo do esperado em função do comportamento dos componentes do PIB (PIB industrial e do PIB OUTROS).

Resumidamente, os resultados apresentados indicam que os Estados tiveram taxas de crescimento no PIB industrial superiores às taxas de São Paulo, bem como aceleração destas taxas na segunda metade da década de 1990. Observa-se comportamento semelhante nas receitas de ICMS, mas não com a mesma intensidade. Isso é coerente com a hipótese de haver perda de receita potencial nos Estados em função dos benefícios fiscais concedidos para as empresas. Os resultados também indicam que as perdas de participação relativa do PIB industrial e da receita

10 Como tendência intermediária considera-se, a grosso modo, uma tendência média entre o PIB industrial e o PIB OUTROS. 
do ICMS em São Paulo ocorreram a partir da segunda metade da década de 1990, o que reforça a hipótese do vínculo com a guerra fiscal.

Tabela 3 - Regressão do PIB industrial nos Estados x SP, e do ICMS nos Estados x SP

\begin{tabular}{|c|c|c|c|c|c|c|c|c|c|}
\hline \multicolumn{5}{|c|}{ PIB Industrial dos Estados x São Paulo } & \multicolumn{5}{|c|}{ ICMS dos Estados x São Paulo } \\
\hline \multirow[t]{2}{*}{ Período } & \multicolumn{4}{|c|}{$1990-1997 / 1998-2004-\theta=1997$} & \multirow[t]{2}{*}{ Período } & \multicolumn{4}{|c|}{$1990-1996 / 1997-2005-\theta=1996$} \\
\hline & MOD 1 & SIG & MOD 2 & SIG & & MOD 1 & SIG & MOD 2 & SIG \\
\hline UF & & & & & UF & & & & \\
\hline BA & 6,33 & * & 0,49 & * & BA & 3,03 & * & 0,82 & * \\
\hline CE & 5,70 & * & 0,17 & $\mathrm{n}$ & CE & 3,17 & * & 0,73 & * \\
\hline PR & 5,32 & * & 0,33 & ** & PR & 2,48 & * & 1,37 & * \\
\hline RJ & 9,23 & * & 1,14 & * & RJ & 3,27 & * & 0,83 & * \\
\hline RS & 4,79 & * & 0,34 & ** & RS & 2,17 & * & 0,94 & * \\
\hline SC & 6,05 & * & 0,30 & $* *$ & SC & 2,97 & * & 0,85 & * \\
\hline ES & 5,66 & * & 0,32 & * & ES & 3,26 & * & 0,70 & * \\
\hline GO & 6,09 & * & 0,37 & * & GO & 3,05 & * & 0,86 & * \\
\hline$M G$ & 5,66 & * & $-0,17$ & $n$ & $M G$ & 2,57 & * & 0,80 & * \\
\hline MS & 5,71 & * & 0,26 & $* *$ & MS & 2,79 & * & 0,93 & * \\
\hline MT & 5,77 & * & 0,30 & $* *$ & MT & 3,20 & * & 0,85 & * \\
\hline TOTAL UF & 10,16 & * & 0,56 & * & TOTAL UF & 3,39 & * & 1,54 & * \\
\hline SP-CAP & 4,53 & * & $-2,23$ & $\mathrm{n}$ & & & & & \\
\hline
\end{tabular}

Obs: SIG $=$ Nível de significância: $={ }^{*}$ significativo até $5 \%,{ }^{*}$ significativo até $10 \%$, n é não significativo.

Gráfico 1 - PIB industrial em São Paulo e TOTAL UF - 1990 a 2004

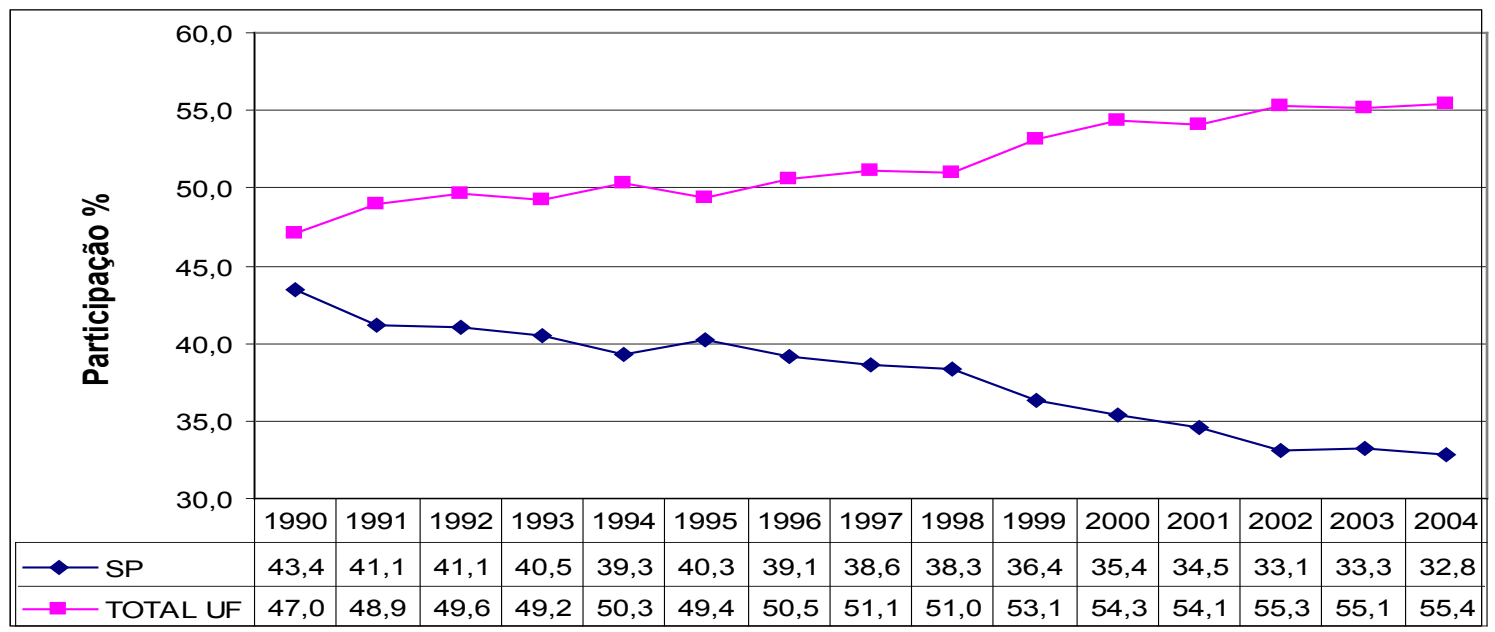

Fonte: IBGE, 2007. 
Gráfico 2 - PIB industrial em São Paulo e na capital paulista - 1980/5, 1996/99 e 2000 a 2004

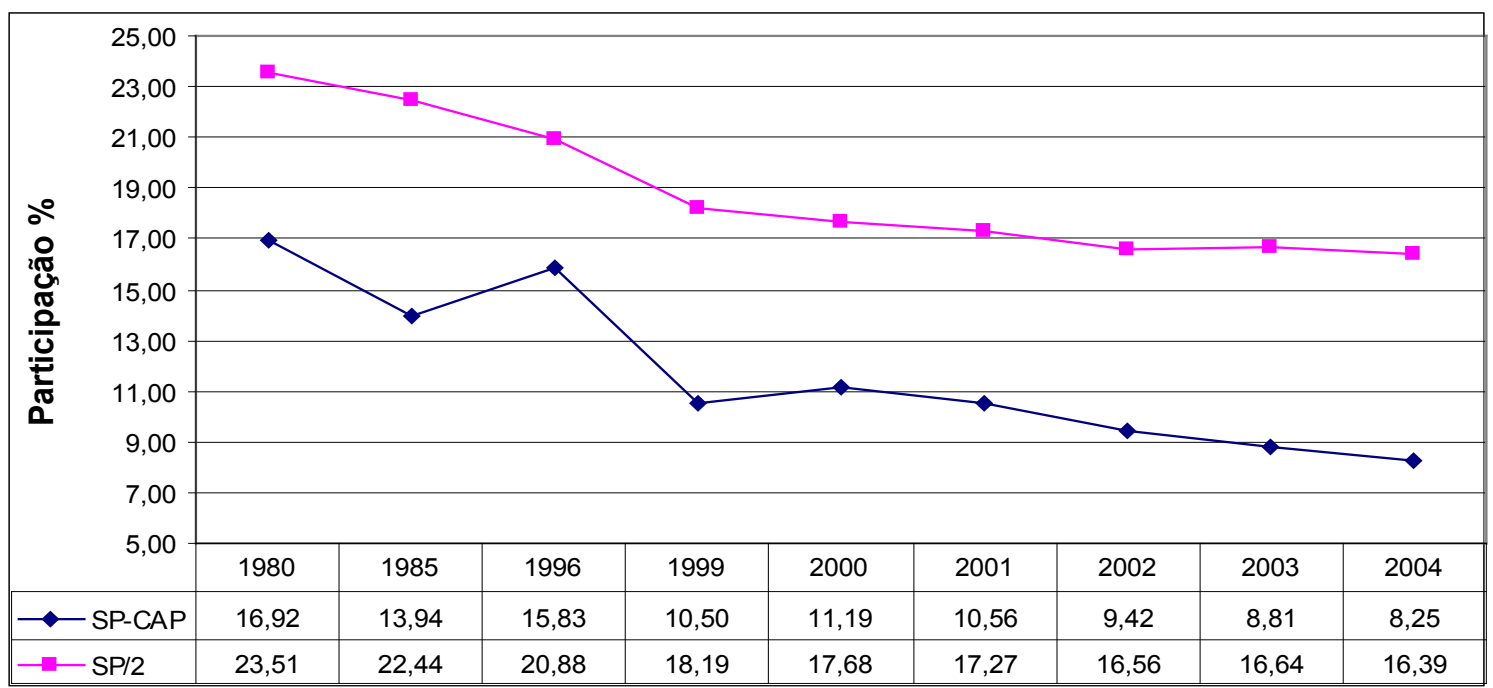

Fonte: IBGE, 2007.

Gráfico 3 - Receita de ICMS nos Estados (TOTAL UF) e receita de ICMS em SP - 1990 a 2004

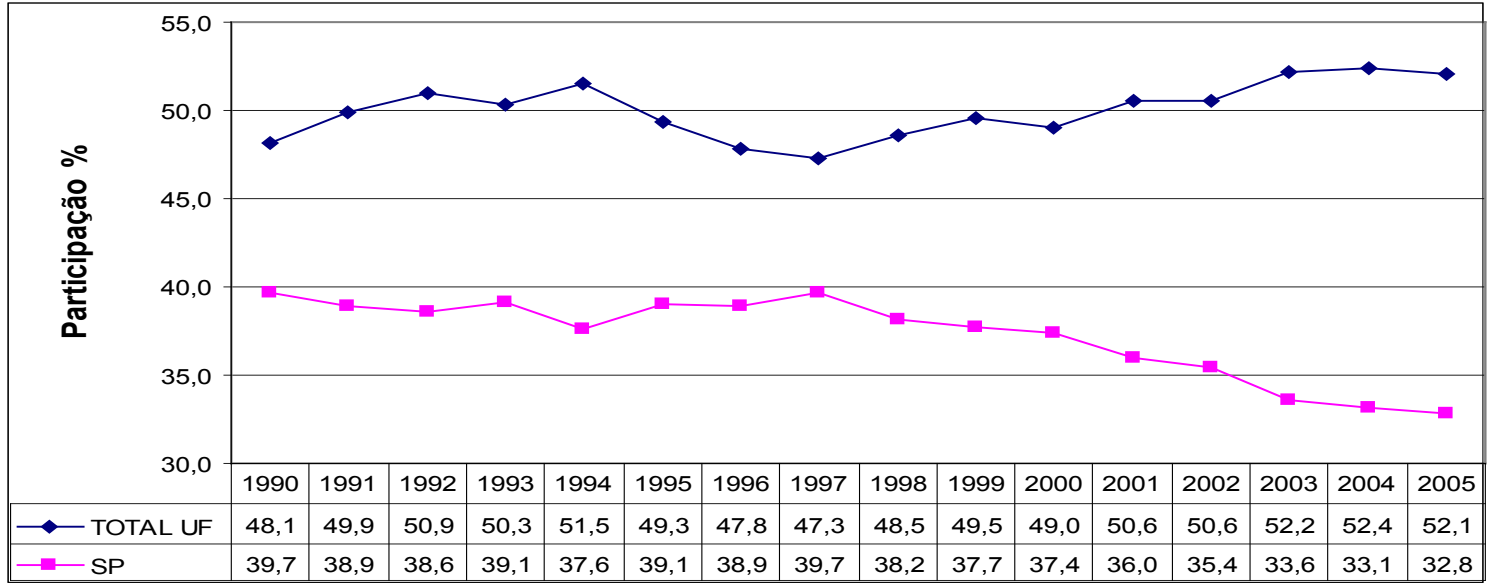

Fonte: IBGE, 2007. 
Gráfico 4 - Receita de ICMS, PIB industrial e PIB nos demais setores (PIB OUT.) em São Paulo e nos Estados (TOT.UF), ${ }^{11}$ como participação porcentual de 1990 a 2004

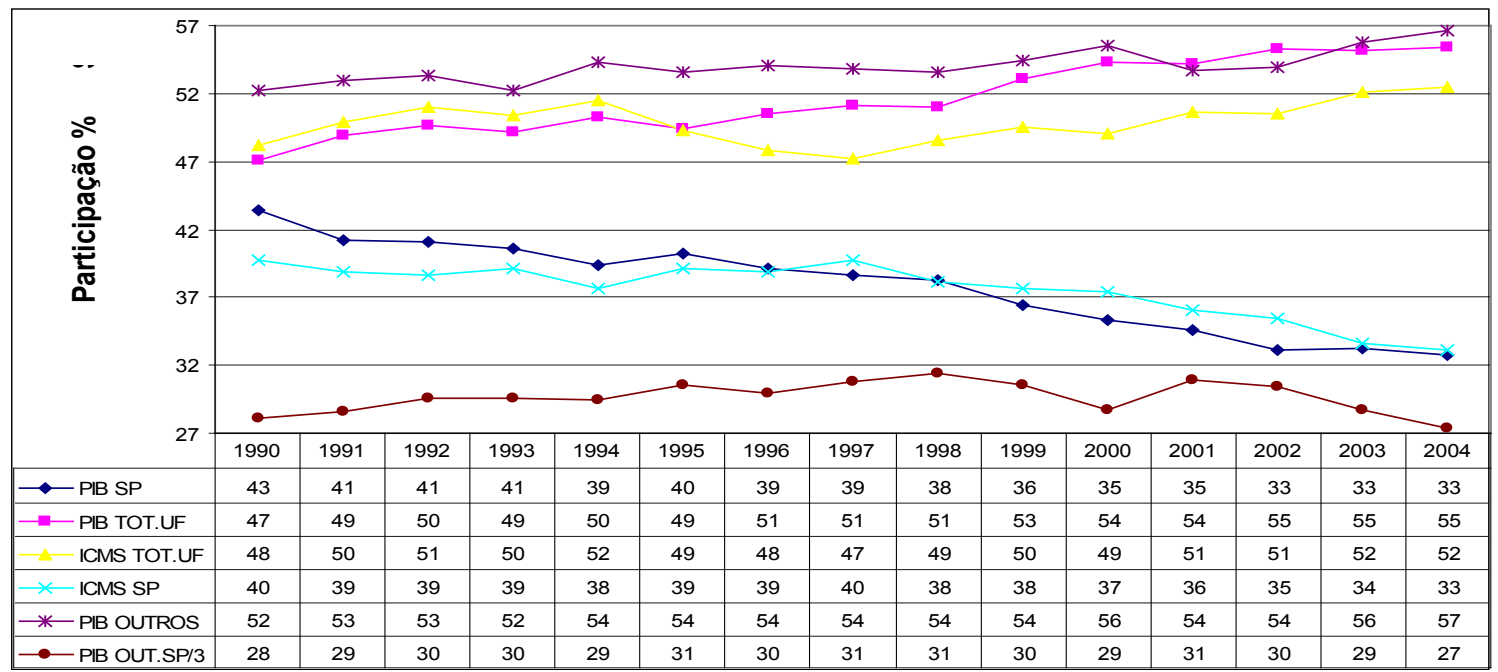

Fonte: IBGE, 2007.

Gráfico 5 - Receita de ICMS, PIB industrial e PIB nos demais setores (PIB OUT.) em São

Paulo e nos Estados (TOT.UF), como base $100=1990$ de 1990 a 2004

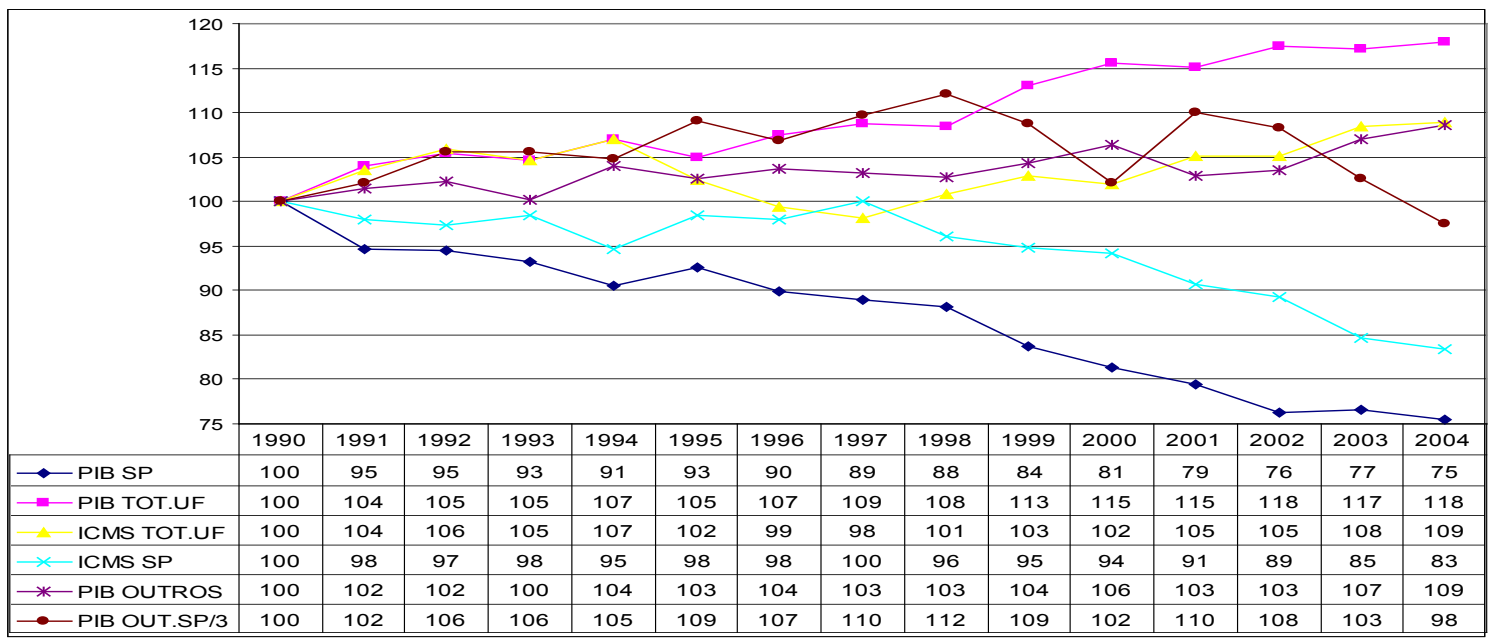

Fonte: IBGE, 2007.

A Tabela 4 apresenta os resultados da geração de empregos no setor industrial, sendo os Estados o grupo de tratamento e São Paulo o de controle. Com este enfoque, objetiva-se iden-

11 Conjunto dos demais Estados analisados, concisamente indicado como UF. 
tificar diferenças significativas na geração de empregos nos Estados em relação a São Paulo, no pós-guerra fiscal.

No modelo 1, nos Estados, assim como no conjunto dos Estados TOTAL UF, o crescimento na geração de novos postos de trabalho, no setor industrial, superou São Paulo. No modelo 2, a aceleração desta taxa é, em geral, negativa e, quando positiva, não é estatisticamente significativa, tanto para os Estados quanto para o TOTAL UF. A análise do Gráfico 6 mostra a crescente tendência na geração de empregos industriais no TOTAL UF, ao longo da década de 1990, ao contrário do Estado de São Paulo, que se mantém com tendência de queda desde 1990. Nota-se que não há alteração substancial no ritmo de crescimento a partir de 1997 e, coerentemente, as estimativas de $\delta_{1}$ não são significativas no modelo 2 , referente ao crescimento do emprego industrial.

Embora a Tabela 3 forneça indicações de que a guerra fiscal afetou o ritmo de crescimento do PIB industrial nos Estados, não há indicações de que ela tenha alterado o ritmo de crescimento do emprego industrial, o que invalida um dos argumentos básicos usados pelos governantes que concedem os benefícios fiscais às empresas.

$\mathrm{Na}$ Tabela 4, é avaliada, também, por Estado, a participação porcentual da geração de empregos industriais, em relação aos OUTROS setores. O objetivo é verificar a possibilidade de os Estados terem gerado mais empregos na indústria, quando comparados aos OUTROS. Como grupo de tratamento, adotou-se a geração de empregos industriais e, como controle, os OUTROS setores.

Para o modelo 1, nos Estados da BA, RJ e SP, o crescimento na geração dos empregos industriais foi inferior a dos OUTROS. No CE, PR, RS, SC, ES, GO, MS e MT, a taxa de crescimento dos empregos industriais superou a dos OUTROS. Já, em MG, não foi significativa a diferença de crescimento dos empregos na indústria em relação aos OUTROS.

No modelo 2, a aceleração da taxa é, em geral, negativa e não é estatisticamente significativa quando positiva. As exceções são São Paulo e Rio de Janeiro que, entretanto, mostram sinal negativo da estimativa de $\beta_{3}$ no modelo 1 .

Comparando a participação porcentual na geração de empregos industriais, no conjunto dos Estados $^{12}$ (TOTAL.UF IND), com os empregos nos demais setores (TOTAL. UF.OUTROS), verifica-se um crescimento na taxa de participação porcentual, nos empregos industriais, de 2,48 p.p. acima da taxa nos demais setores, porém, sem alterações significativas na diferença de crescimento entre estas taxas ao longo da década de 1990, conforme Tabela 3 e Gráfico 7.

12 O TOTAL UF IND e o TOTAL UF OUTROS foram obtidos pela soma dos Estados, excluindo-se São Paulo. 
Avaliando o Gráfico 8, observa-se que a participação do Estado de São Paulo na geração de empregos industriais sofre queda ao longo de toda a década de 1990, enquanto que a participação dos demais setores se mantém relativamente constante.

Resumidamente, pode-se afirmar que São Paulo perdeu participação na geração de empregos na indústria ao longo da década de 1990, mantendo constante a sua participação nos empregos dos demais setores. Em contrapartida, estes novos postos de trabalho foram abertos em outros Estados. Este fenômeno ocorreu sem alterações na tendência durante toda a década de 1990 e, por isso, não pode ser associado à guerra fiscal. Enquanto os dados indicam mudanças de tendência na produção industrial dos Estados no pós-guerra fiscal, não indicam alterações expressivas na geração de novos postos de trabalho nas indústrias.

\section{Tabela 4 - Regressão dos empregos industriais nos Estados x SP e x empregos em outros setores}

\begin{tabular}{|c|c|c|c|c|c|c|c|c|c|}
\hline \multicolumn{5}{|c|}{ Emprego industrial nos Estados x São Paulo } & \multicolumn{5}{|c|}{ Emprego industrial $x$ Outros empregos nos Estados } \\
\hline \multirow[t]{2}{*}{ Período } & \multicolumn{4}{|c|}{ 1990-1997 / 1998-204 - $\theta=1997$} & \multirow[t]{2}{*}{ Período } & \multicolumn{4}{|c|}{$1990-1997 /$ 1998-204 - $\theta=1997$} \\
\hline & MOD 1 & SIG & MOD 2 & SIG & & MOD 1 & SIG & MOD 2 & SIG \\
\hline UF & & & & & UF & & & & \\
\hline BA & 6,91 & * & $-0,09$ & $\mathrm{n}$ & $\mathrm{BA}$ & $-0,20$ & ** & 0,07 & $\mathrm{n}$ \\
\hline CE & 7,43 & * & $-0,21$ & $n$ & CE & 0,80 & * & $-0,01$ & $n$ \\
\hline PR & 8,33 & * & $-0,24$ & ** & PR & 1,61 & * & 0,07 & $\mathrm{n}$ \\
\hline RJ & 4,34 & * & $-0,12$ & $n$ & RJ & $-0,97$ & * & 0,09 & * \\
\hline RS & 7,24 & * & 0,20 & $n$ & $\mathrm{RS}$ & 1,09 & * & 0,01 & $n$ \\
\hline SC & 7,88 & * & 0,21 & $n$ & SC & 1,02 & * & $-0,09$ & * \\
\hline ES & 6,77 & * & $-0,22$ & $n$ & ES & 0,11 & * & $-0,05$ & * \\
\hline GO & 7,38 & * & $-0,20$ & $n$ & GO & 0,37 & * & $-0,05$ & * \\
\hline MG & 7,65 & * & $-0,52$ & * & MG & 0,29 & $n$ & $-0,17$ & * \\
\hline MS & 6,81 & * & $-0,18$ & $n$ & MS & 0,17 & * & 0,01 & $n$ \\
\hline MT & 7,04 & * & $-0,23$ & $n$ & MT & 1,68 & * & $-0,12$ & ** \\
\hline- & - & - & - & - & $\mathrm{SP}$ & $-5,41$ & * & 0,43 & * \\
\hline TOTAL UF & 12,59 & * & $-0,25$ & $n$ & TOTAL UF & 2,48 & * & $-0,41$ & $n$ \\
\hline
\end{tabular}

Obs: SIG = Nível de significância: * significativo até 5\%, ** significativo até $10 \%$, n é não significativo. 
Gráfico 6 - Geração de empregos industriais nos Estados (TOTAL UF) x empregos industriais em São Paulo - 1990 a 2004

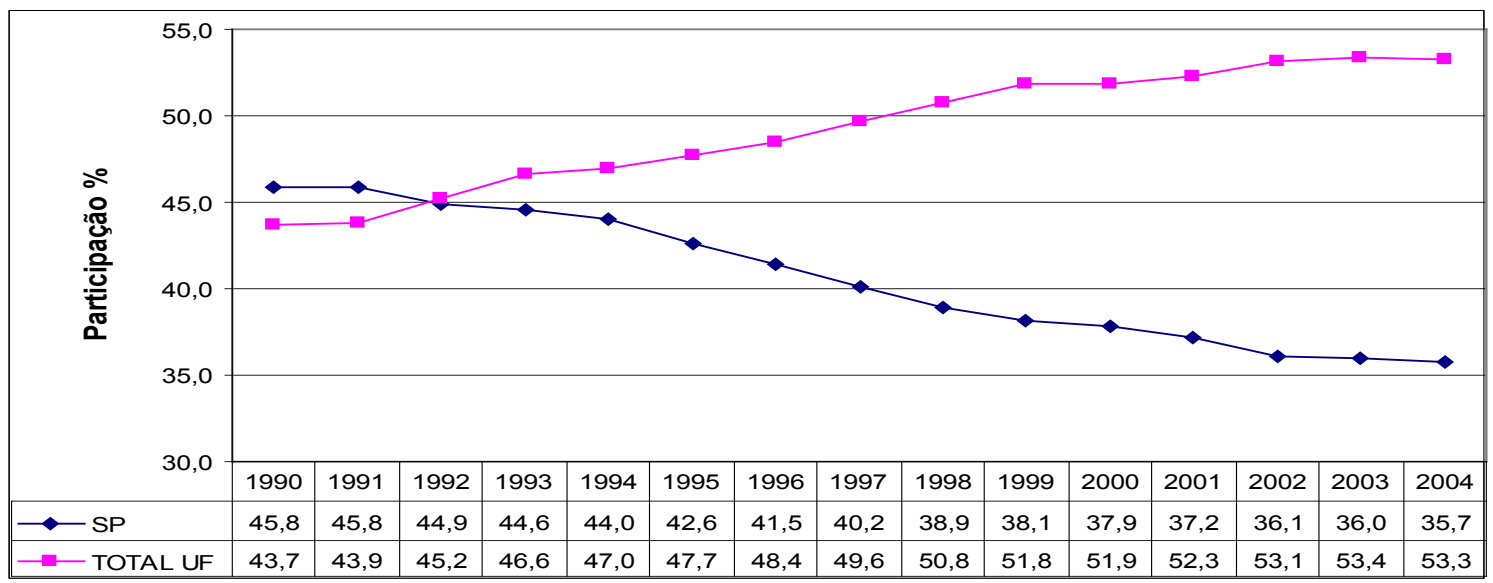

Fonte: IBGE, 2007.

Gráfico 7 - Geração de empregos industriais nos Estados (TOT UF.IND) e geração de outros empregos nos Estados (TOT UF.OUTROS) - 1990 a 2004

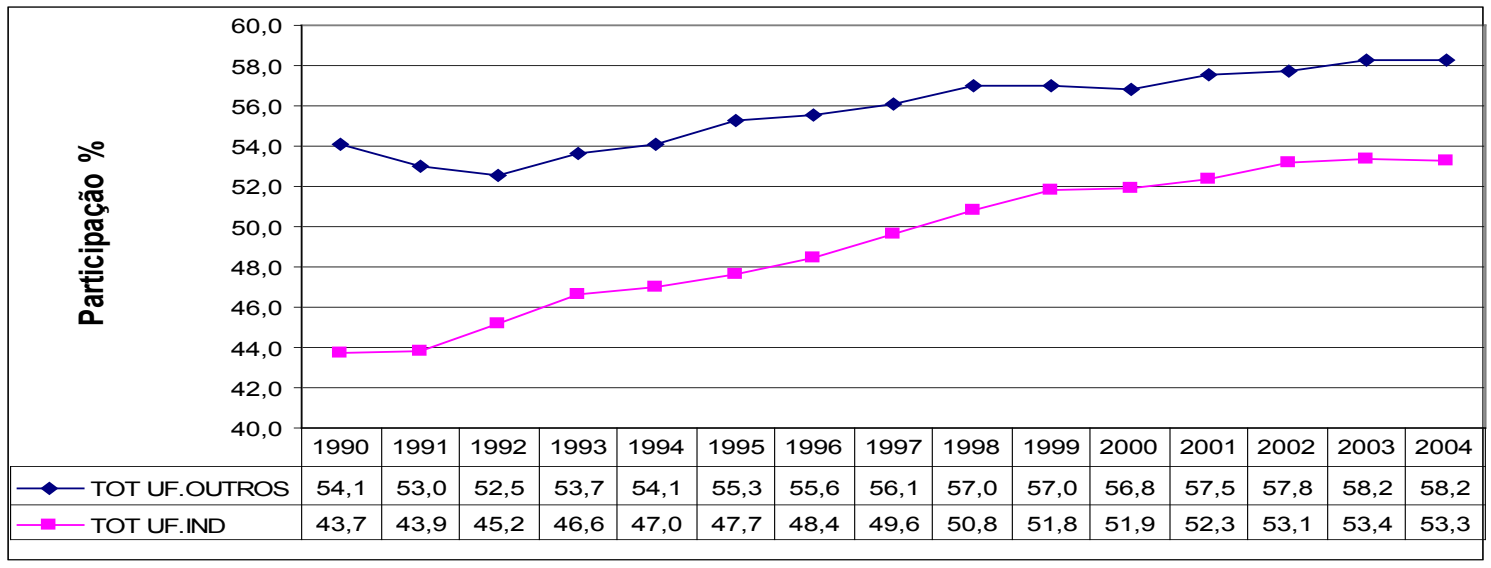

Fonte: IBGE, 2007. 
Gráfico 8 - Geração de empregos industriais (EMP.IND.SP) x empregos nos demais setores (EMP.OUT) no Estado de São Paulo - 1990 a 2004

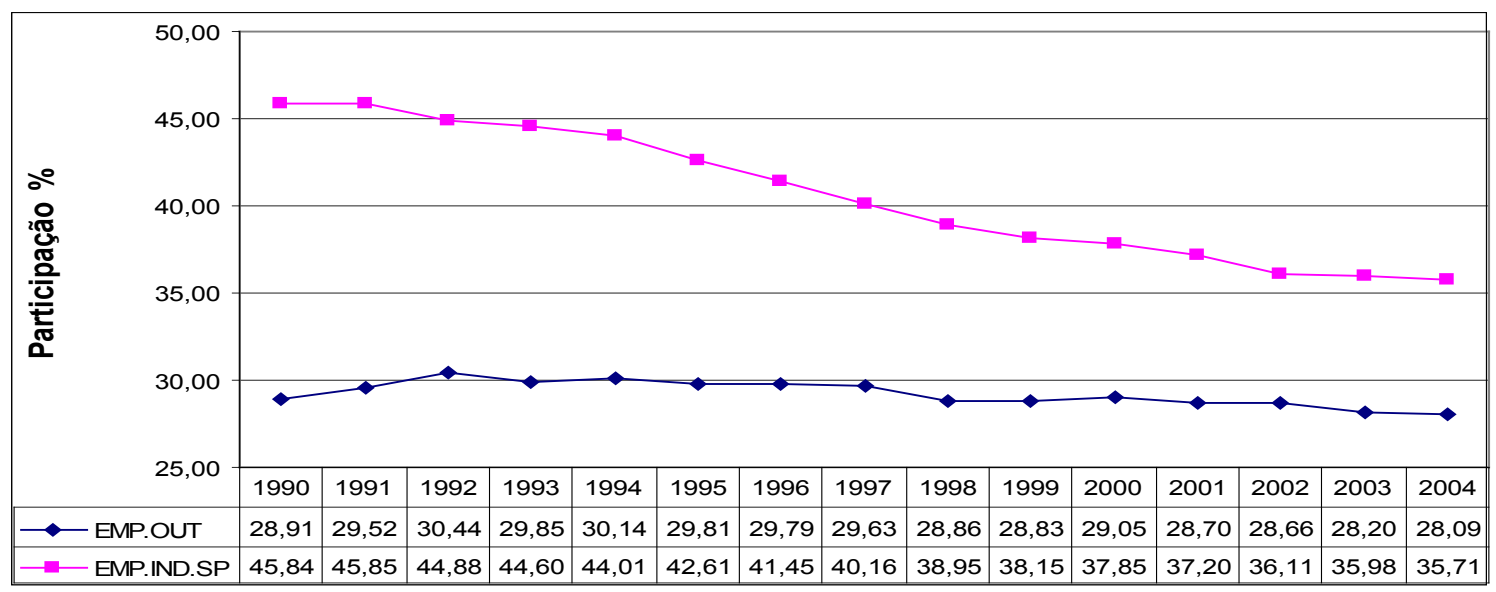

Fonte: IBGE, 2007.

$\mathrm{Na}$ Tabela 5, a variável PIB industrial representa o grupo de tratamento, e o PIB OUTROS, o grupo de controle. O PIB OUTROS representa a participação porcentual da soma do PIB comercial, do PIB de serviços e do PIB agrícola de cada Estado em relação à soma no Brasil.

Este procedimento, para o modelo 1, detecta variações diferenciadas na taxa de participação porcentual do PIB industrial em relação à participação dos demais setores da economia em cada Estado. $\mathrm{O}$ modelo 2 detecta diferenças na aceleração da taxa de crescimento dessas variáveis, no segundo período.

Os resultados do modelo 1 mostram que, na BA e RJ, a taxa de crescimento da participação porcentual no PIB industrial supera a taxa do PIB OUTROS, no pós-guerra fiscal. Para os Estados do PR, ES, RS, MT e SP, o crescimento do PIB industrial foi inferior ao PIB OUTROS, para os demais Estados as mudanças não foram significativas.

A aceleração da taxa de crescimento do PIB industrial, em relação ao PIB OUTROS, é, em alguns casos, negativa e, quando positiva, não é significativa, com exceção apenas do RJ, ES, BA e SP, que apresentam aceleração de 0,67, 0,06, 0,12 e 0,60 p.p. ao ano, respectivamente, conforme o modelo 2.

Avaliando o TOTAL UF, no modelo 1, os resultados indicam crescimento, na taxa de participação do PIB industrial, em média, 3,32 p.p. acima do crescimento da taxa no PIB OUTROS. Já no modelo 2, a aceleração desta taxa, no segundo período, não foi significativa. Sendo assim, para a maioria dos Estados e para o seu conjunto (TOTAL UF), a mudança na taxa de crescimento do PIB industrial não difere dos demais setores, nos dois períodos analisados. 
Visando identificar se o crescimento na participação do PIB industrial foi acompanhado pelo crescimento das receitas de ICMS, adotou-se, como grupo de tratamento, a participação porcentual do PIB industrial, e a participação na arrecadação de ICMS, como grupo de controle.

A Tabela 5 mostra os resultados para o modelo 1, onde apenas os Estados ${ }^{13}$ da Bahia, Rio de Janeiro, Santa Catarina e Goiás apresentam taxas de crescimento do PIB industrial superiores às taxas de crescimento na arrecadação do ICMS. ${ }^{14}$

No modelo 2, os dados indicam que, apenas na Bahia, Rio de Janeiro, Espírito Santo e São Paulo, a aceleração na taxa de crescimento da participação porcentual do PIB industrial foi positiva e significativa, quando comparada à aceleração da receita de ICMS.

Para o TOTAL UF, o modelo 1 mostrou crescimento médio, na taxa de participação do PIB industrial, de 4,52 p.p. acima da taxa do ICMS. No Estado de São Paulo, o PIB industrial demonstrou queda de 2,57 p.p. em relação à receita de ICMS, no segundo período.

O modelo 2 indica ser de 0,54 p.p. ao ano a aceleração da taxa de crescimento no PIB industrial em relação à receita de ICMS no Estado paulista, e que esta não foi significativa no conjunto dos Estados (TOTAL UF).

Os Gráficos 9 e 10 indicam a tendência das variáveis ICMS e PIB OUTROS em relação ao PIB industrial no Estado de São Paulo, e estes confirmam os resultados da Tabela 5, ou seja, o Estado paulista, na segunda metade da década de 1990, perde participação no PIB industrial e na receita de ICMS, mantendo a sua participação constante do PIB dos outros setores. Sendo assim, é possível associar a queda na receita com a redução da produção industrial.

13 A explicação para os acréscimos na arrecadação do ICMS, no Estado do Paraná, pode estar no fato de que, em 2002, ocorreu um acréscimo significativo na alíquota deste imposto, portanto, o bom desempenho tributário não está relacionado aos aumentos na produção e sim aos aumentos de alíquotas.

14 Como já discutido anteriormente, o Estado pode estimular a migração de empresas por meio de benefícios financeiros, sendo assim, a arrecadação de ICMS deverá ter acréscimos compatíveis com os acréscimos na produção. Por outro lado, devem aumentar as despesas com infra-estrutura e com a concessão de empréstimos às empresas. Estes itens não fazem parte desta pesquisa, principalmente pela dificuldade na mensuração dos dados. 
Tabela 5 - Regressão do PIB industrial nos Estados x receita de ICMS e x PIB em outros setores -1990 a 2004

\begin{tabular}{|c|c|c|c|c|c|c|c|c|c|}
\hline \multicolumn{5}{|c|}{ PIB industrial $x$ ICMS nos Estados } & \multicolumn{5}{|c|}{ PIB industrial x PIB Outros (média) Estados } \\
\hline \multirow[t]{2}{*}{ Período } & \multicolumn{4}{|c|}{$1990-1997 /$ 1998-2004 - $\theta=1997$} & \multirow[t]{2}{*}{ Período } & \multicolumn{4}{|c|}{ 1990-1997 / 1998-2004 - $\theta=1997$} \\
\hline & MOD 1 & SIG & MOD 2 & SIG & & MOD 1 & SIG & MOD 2 & SIG \\
\hline UF & & & & & UF & & & & \\
\hline BA & 0,49 & ** & 0,12 & * & BA & 0,81 & * & 0,12 & * \\
\hline CE & $-0,23$ & ** & $-0,09$ & * & CE & 0,10 & $\mathrm{n}$ & $-0,14$ & * \\
\hline PR & $-0,14$ & $\mathrm{n}$ & $-0,62$ & * & PR & $-0,99$ & * & 0,03 & $\mathrm{n}$ \\
\hline RJ & 2,89 & * & 0,75 & * & RJ & 4,82 & * & 0,67 & * \\
\hline RS & $-0,27$ & $\mathrm{n}$ & $-0,13$ & $\mathrm{n}$ & $\mathrm{RS}$ & $-1,23$ & * & 0,09 & $n$ \\
\hline SC & 0,34 & * & $-0,06$ & $n$ & SC & 0,18 & $n$ & $-0,04$ & $n$ \\
\hline ES & $-0,19$ & $\mathrm{n}$ & 0,14 & * & ES & $-0,17$ & ** & 0,06 & * \\
\hline GO & 0,26 & * & $-0,02$ & $n$ & GO & 0,20 & $n$ & $-0,05$ & $n$ \\
\hline$M G$ & 0,39 & $n$ & $-0,46$ & * & $M G$ & 0,01 & $n$ & $-0,42$ & * \\
\hline MS & 0,14 & $n$ & $-0,18$ & * & MS & $-0,11$ & $n$ & $-0,07$ & * \\
\hline MT & $-0,15$ & $n$ & $-0,08$ & * & MT & $-0,30$ & * & $-0,11$ & * \\
\hline SP & $-2,57$ & * & 0,54 & * & $\mathrm{SP}$ & $-5,14$ & * & 0,60 & * \\
\hline TOTAL UF & 4,52 & * & 0,45 & $\mathrm{n}$ & TOTAL UF & 3,32 & * & 0,14 & $\mathrm{n}$ \\
\hline
\end{tabular}

Obs: SIG = Nível de significância: * significativo até 5\%, ** significativo até $10 \%$, n é não significativo.

Gráfico 9 - Receita de ICMS e PIB industrial no Estado de São Paulo - 1990 a 2004

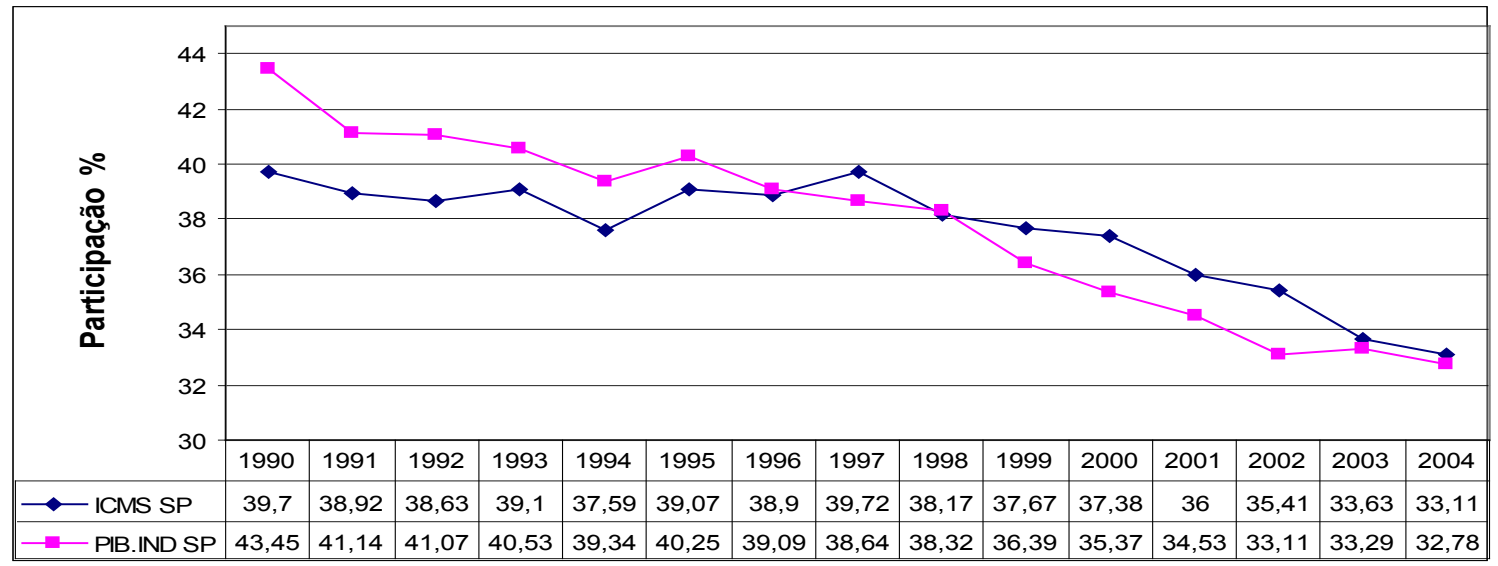

Fonte: IBGE, 2007. 


\section{Gráfico 10 - PIB industrial e PIB outros setores no Estado de São Paulo - 1990 a 2004}

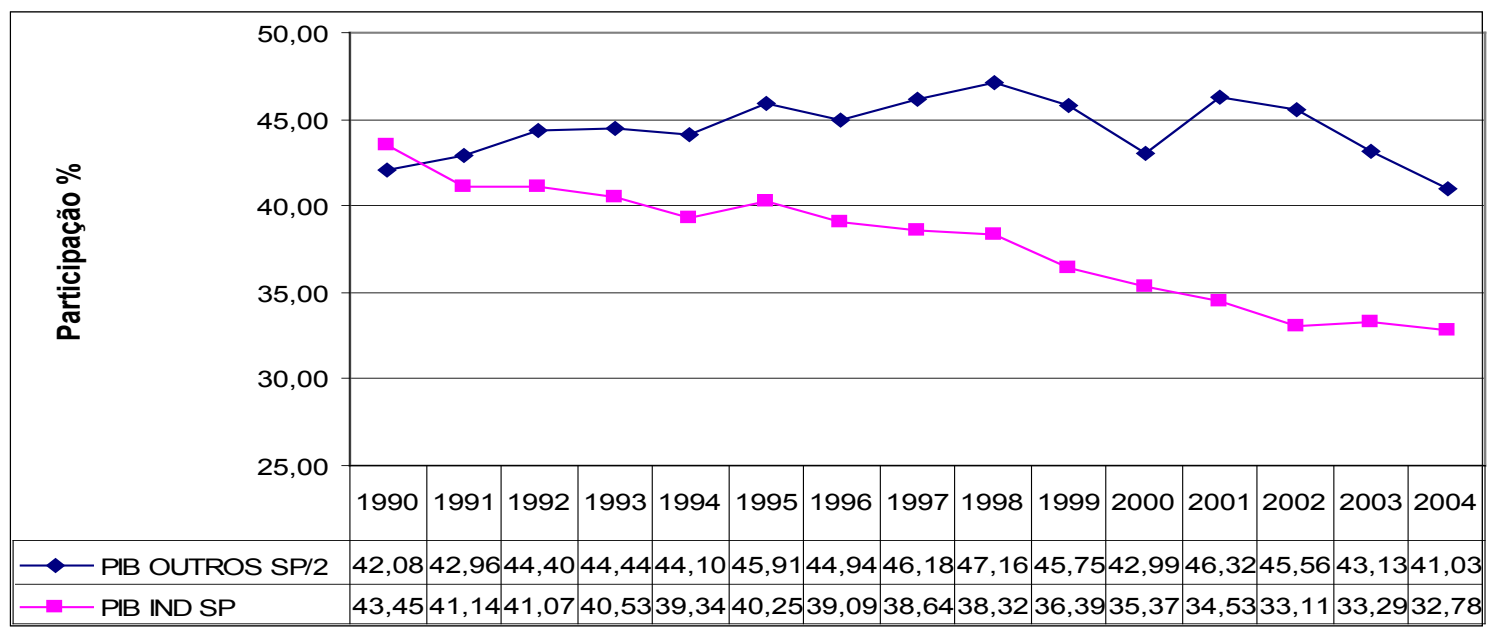

Fonte: IBGE, 2007.

\section{CONSIDERAÇÕES FINAIS}

O principal objetivo desta pesquisa foi encontrar evidências empíricas, em alguns Estados da Federação, que refletissem o ambiente competitivo instalado no Brasil, após a segunda metade da década de 1990.

Os resultados dos modelos econométricos mostraram que as taxas de crescimento na participação porcentual da produção industrial nos Estados foram superiores às de São Paulo. Estas, por sua vez, indicam comportamento crescente nos Estados e decrescente em São Paulo na segunda metade da década de 1990. Analisando o conjunto dos Estados, estes resultados mostram-se mais expressivos. Individualmente, os resultados desta pesquisa destacam a BA e o RJ como os Estados que obtiveram os melhores resultados para o setor industrial, e SP e MG, os piores resultados.

Ao avaliar a participação porcentual na geração de empregos industriais, os resultados indicam que as taxas de crescimento nos Estados foram superiores às taxas em São Paulo, e mantiveram-se constantes ao longo da década de 1990. Portanto, nos Estados, o crescimento da produção industrial não foi acompanhado pela geração de novos postos de trabalho nas mesmas proporções, na segunda metade da década. Não há evidências de que a guerra fiscal tenha alterado significativamente a tendência de geração de empregos industriais nos Estados.

As taxas de crescimento da participação dos demais Estados na arrecadação do ICMS foram superiores às de São Paulo. A análise gráfica mostra certa estabilidade nos Estados e queda 
expressiva de participação na receita em São Paulo, na segunda metade da década de 1990, o que indica perda de receita potencial nos Estados.

A estabilidade econômica, a abertura comercial, o desenvolvimento comercial e agrícola e a evolução das relações comerciais no MERCOSUL também foram fatores que interferiram na economia na década analisada. Entretanto, estes dificilmente afetariam, de forma tão diferenciada, o Estado de São Paulo em relação aos demais Estados, principalmente no período em que estes, declaradamente, entram na disputa por investimentos.

Sendo assim, é bastante razoável aceitar que o processo da guerra fiscal afetou diretamente São Paulo na segunda metade da década de 1990. Isto foi amplamente divulgado. Foram várias as tentativas do governo Covas para conter a migração de empresas paulistas para os demais Estados, utilizando, inclusive, ações de inconstitucionalidade impetradas no Supremo Tribunal de Justiça, as quais questionavam alguns programas de incentivo aos investimentos adotados pelos Estados, além da proibição de as empresas paulistas utilizarem o crédito de ICMS de fornecedores que foram beneficiados em outras UF.

Portanto, os fenômenos analisados nesta pesquisa têm uma ligação forte com os incentivos fiscais e financeiros. É verdade que outros fatores, inerentes a cada Estado, podem ter afetado o seu desempenho, como, por exemplo, a expansão agrícola na região Centro-Oeste. Ainda assim, as empresas que se desenvolveram ou migraram para esta região certamente apropriaram-se dos benefícios fiscais concedidos por esses Estados, os quais, de qualquer forma, renunciaram a uma parcela de receita potencial, contribuindo para a queda da receita do ICMS no Estado de São Paulo.

As avaliações sobre o tema não foram esgotadas no artigo e muitas comparações podem ainda ser elaboradas de forma a diferenciar os impactos por Estado e por tipo de benefício. Há poucas pesquisas empíricas em torno do tema abordado, em função principalmente da complexidade em se mensurar impactos gerados por determinadas políticas públicas; logo, esperase, com este artigo, ter contribuído para melhor qualificar os impactos da "guerra fiscal" nos Estados analisados.

\section{REFERÊNCIAS}

ALVES, M. A. da S. Guerra fiscal e finanças federativas no Brasil: o caso do setor automotivo. 2001. 111 p. Dissertação (Mestrado em Economia) - Universidade Estadual de Campinas, Campinas, 2001.

ANGRIST, D. J.; KRUEGER, A.B. Empirical strategies in labor economics. Princeton University, 1998, Amsterdam, p. 1277-1366 (Working Paper, 401).

ARBIX, G. Desamparo institucional e despreparo governamental na guerra fiscal brasileira. II Seminário Internacional da USP - Brasil, México, África do Sul, Índia e China: Estratégias de Integração e Desenvolvimento. 2001. 
BRASIL/MTE. Relatórios Anuais de Informação Sociais (RAIS/CAGED). Brasília: Ministério do Trabalho e Emprego, 1990-2004

CARVALHO, J. R.; OLIVEIRA, V. H. Fundo de desenvolvimento industrial do Ceará: uma avaliação econométrica com dados em painel para o período de 1995 a 2001. Estudos Econômicos, Fortaleza, n. 47, p. 12-14, 2003. (Texto para Discussão, 47)

DEBACO, E. S.; JORGE NETO, P. de M. Competição entre os Estados por investimentos privados. Cidade: Centro de Estudos de Economia Regional. CAEN/UFC, 1998. 14 p. (Texto de Discussão, 180).

FERREIRA, Sérgio G.. Reforma tributária Guerra fiscal: competição tributária ou corrida ao fundo do tacho? Informe-se, n. 4, jan. 2000. Disponível em: <http://www.federativo.bndes.gov.br/f_informes. htm>. Acesso em: fev. 2007.

HILLBRECHT, R. Federalismo e a união monetária brasileira. Estudos Econômicos. São Paulo, v. 27, n. 1, p. 35-67, jan.-abr. 1997.

HOFFMANN, R. Análise de regressão: uma introdução à econometria. 4. ed. São Paulo: Hucitec, 2006. $378 \mathrm{p}$.

HULTEN, C.R.; SCHWAB, R. M. A fiscal federalism approach to infrastructure policy. Regional Science and Urban Economics, v. 27, p.139-159, 1997.

INSTITUTO BRASILEIRO DE GEOGRAFIA E ESTATÍSTICA - IBGE. Contas regionais. Disponível em: <http://www.ibge.gov.br>. Acesso em: 10 nov. 2007.

. Perfil dos municípios brasileiros - gestão pública 2006. Disponível em: <http://www.ibge.gov. br>. Acesso em: 18 jan. 2008.

IPEADATA. Dados macroeconômicos e regionais. Disponível em: <http://www.ipeadata.gov.br >. Acesso em: 10 fev. 2007.

LENGRUBER, A. A competição tributária em economias federativas: aspectos teóricos, constatações empíricas e uma análise do caso brasileiro. 1999. 89 p. Dissertação (Mestrado em Economia) - Universidade de Brasília, Brasília, 1999.

NASCIMENTO, S. P. Guerra fiscal: causas, conseqüências e perspectivas futuras: uma análise para o Estado do Paraná. 2002. 60 p. Dissertação (Mestrado em Economia) - Instituto de Economia, Universidade de Brasília, Brasília, 2002.

NOGUEIRA, C.; JORGE NETO, P. M. N. Os impactos dos incentivos fiscais sobre a estrutura industrial e sobre a competitividade das firmas. Fortaleza: UFC, Centro de Estudos de Economia Regional, 1998. 20 p. (Texto de Discussão, 178).

PERIUS, K. C. G. A concessão de incentivos fiscais estaduais e a nova lei de responsabilidade fiscal no federalismo brasileiro. 2002. 87 p. Monografia (Trabalho de Conclusão de Curso de Direito) - Universidade do Vale do Rio dos Sinos Unisinos, São Leopoldo, 2002.

PRADO, S.; CAVALCANTI, E. G. C. A guerra fiscal no Brasil. São Paulo: FUNDAP; FAPESP; Brasília: IPEA, 2000. 146 p. (Federalismo no Brasil) . Aspectos da guerra fiscal no Brasil. São Paulo: IPEA, 1998. 89 p.

SAPIENZA, V; TORRES, D; CARVALHO, J. E. L. Guerra fiscal: com ela todos perdem. 2. ed. São Paulo: Sinafresp/Afresp, 1998. $151 \mathrm{p}$.

SUZIGAN, W; FURTADO, J. Política industrial e desenvolvimento. Revista de Economia Política, v. 26, p. 163-185, abr.-jun. 2006

TYLER, W. Promoting economic growth in Ceará: a background paper for the World Bank's Ceará State Economic Memorandum. [S.l.: s.n.], 1998. 
VARIAN, Hal R. Microeconomia: princípios básicos. Rio de Janeiro: Campus, 1994. Tradução da 2. ed. de: Luciane Melo.

VARSANO, R. A guerra fiscal do ICMS: quem ganha e quem perde. Rio de Janeiro: IPEA, 1997. 13 p. (Texto para Discussão, 500).

WOOLDRIDGE, J. Econometric analysis of cross section and panel data. Cambridge: The MIT Press, 2001. $735 \mathrm{p}$. 